\title{
ACTIVE PERSONAL DOSEMETERS IN INTERVENTIONAL RADIOLOGY: TESTS IN LABORATORY CONDITIONS AND IN HOSPITALS
}

\author{
I. Clairand ${ }^{1, *}$, J.-M. Bordy ${ }^{2}$, J. Daures ${ }^{2}$, J. Debroas ${ }^{1}$, M. Denozière ${ }^{2}$, L. Donadille ${ }^{1}$, M. Ginjaume ${ }^{3}$, C. Itié ${ }^{1}$, \\ C. Koukorava ${ }^{4}$, S. Krim ${ }^{5}$, A.-L. Lebacq ${ }^{5}$, P. Martin ${ }^{6}$, L. Struelens ${ }^{5}$, M. Sans-Mercé ${ }^{7}$, M. Tosic ${ }^{7}$ and $^{2}$ \\ F. Vanhavere ${ }^{5}$ \\ ${ }^{1}$ Institut de Radioprotection et de Sûreté Nucléaire (IRSN), BP17, 92262 Fontenay-aux-Roses, France \\ ${ }^{2}$ CEA-LIST Laboratoire National Henri Becquerel (CEA-LNHB), CEA Saclay, 91191 Gif sur Yvette, \\ France \\ ${ }^{3}$ Universitat Politècnica de Catalunya (UPC), Diagonal 647, 08028 Barcelona, Spain \\ ${ }^{4}$ Greek Atomic Energy Commission (GAEC), Ag. Paraskevi, 15310 Athens, Greece \\ ${ }^{5}$ Belgian Nuclear Research Centre (SCK•CEN), Boeretang 200, 2400 Mol, Belgium \\ ${ }^{6}$ Mirion Technologies (MGPI) SA Route d'Eyguières, 13113 Lamanon, France \\ ${ }^{7}$ Institut Universitaire de Radiophysique Appliquée (IRA), Grand Pré 1, 1007 Lausanne, Switzerland \\ *Corresponding author: isabelle.clairand@irsn.fr
}

\begin{abstract}
The work package 3 of the ORAMED project, Collaborative Project (2008-11) supported by the European Commission within its seventh Framework Programme, is focused on the optimisation of the use of active personal dosemeters (APDs) in interventional radiology and cardiology (IR/IC). Indeed, a lack of appropriate APD devices is identified for these specific fields. Few devices can detect low-energy $\mathrm{X}$ rays $(20-100 \mathrm{keV})$, and none of them are specifically designed for working in pulsed radiation fields. The work presented in this paper consists in studying the behaviour of some selected APDs deemed suitable for application in IR/IC. For this purpose, measurements under laboratory conditions, both with continuous and pulsed X-ray beams, and tests in real conditions on site in different European hospitals were performed. This study highlights the limitations of APDs for this application and the need of improving the APD technology so as to fulfil all needs in the IR/IC field.
\end{abstract}

\section{INTRODUCTION}

The optimisation of the use of active personal dosemeters (APDs) in interventional radiology and cardiology (IR/IC) is performed by one of the work packages of the ORAMED project, a Collaborative Project $^{(1)}(2008-11)$ supported by the European Commission within its seventh Framework Programme.

APDs are used for monitoring of occupational exposure in many applications involving ionising radiation, especially in the nuclear industry. In hospital environments, they are much less used ${ }^{(2)}$. In IR/IC, the possibility of assessing the dose and/or dose rate in real-time is particularly interesting since operators can receive relatively high doses while standing close to the primary radiation field. In addition, an attractive feature of the APD is the possibility of having an alarm when a particular dose rate or dose value is exceeded. Due to the specificity of the X-ray fields used in IR/IC (low energies and pulsed fields), the current technology of APDs can be inadequate. This problem was highlighted during two previous international intercomparisons ${ }^{(3-5)}$.
The work presented in this paper consisted in:

- studying the real radiation field characteristics encountered in IR/IC in terms of energy, angular distribution, dose rate and pulse characteristics;

- making a selection of commercial APDs deemed suitable for application in IR/IC according to several criteria, in particular the capacity to respond to photon energies down to $20 \mathrm{keV}$;

- testing, under laboratory reference conditions, the dose, dose rate, energy and angular response of the selected APDs;

- studying, under laboratory reference conditions, the effect of the dose rate, pulse frequency and pulse width on the APD response;

- performing tests in several European hospitals under workplace conditions.

\section{MATERIALS AND METHODS}

\section{Typical fields in IR/IC}

The typical fields and parameters encountered in IR/IC were gathered through questionnaires sent to 


\section{CLAIRAND ET AL.}

hospitals, a literature search and quality control outputs. Calculations of the dose equivalent rate at specific points of interest and typical scattered spectra were performed using the Monte Carlo codes MCNPX and PENELOPE ${ }^{(6,7)}$.

\section{Selection of APDs}

The selection of commercial APD models was based on the results from international intercomparisons ${ }^{(3-5)}$, and on their availability in different European countries. A prerequisite for consideration was that each device should respond to photon energies down to $20 \mathrm{keV}$. Following those criteria, seven commercial APDs were selected (Figure 1): DMC 2000XB (MGPi), EPD Mk2.3 (Thermo), EDM III (Dosilab), PM1621A (Polimaster), DIS-100 (Rados), EDD30 (Unfors) and AT3509C (Atomtex).

\section{Tests of APDs under laboratory conditions}

The tests with continuous X-ray fields were made in two calibration laboratories (IRSN in France and $\mathrm{SCK} \bullet \mathrm{CEN}$ in Belgium). These tests were performed to determine the dose, energy, dose rate and angle responses of the above-mentioned APDs. Two devices of each type were always used. The following reference fields were used $(\mathrm{N}-15, \mathrm{~N}-20, \mathrm{~N}-25, \mathrm{~N}-30$, N-40, N-60, N-80, N-100, N-120, S-Cs and S-Co) as defined in the ISO $4037-1^{(8)}$ standard.

The tests ${ }^{(9)}$ in a pulsed mode were made at the French standard laboratory for ionising radiation (Laboratoire National Henri Becquerel-LNHB, CEA LIST in France). The influence of several parameters on the response of the APD in a pulsed mode was studied (70 kVp, HVL $5.17 \mathrm{~mm} \mathrm{Al}$ ):

- the effect of the dose equivalent rate (i.e. the mean dose equivalent rate during one pulse) from 1 to $55 \mathrm{~Sv} \mathrm{~h}{ }^{-1}$ for a pulse duration $=20$ $\mathrm{ms}$ and a pulse frequency $=10 \mathrm{~s}^{-1}$ (tests were performed in a multi-pulsed mode);

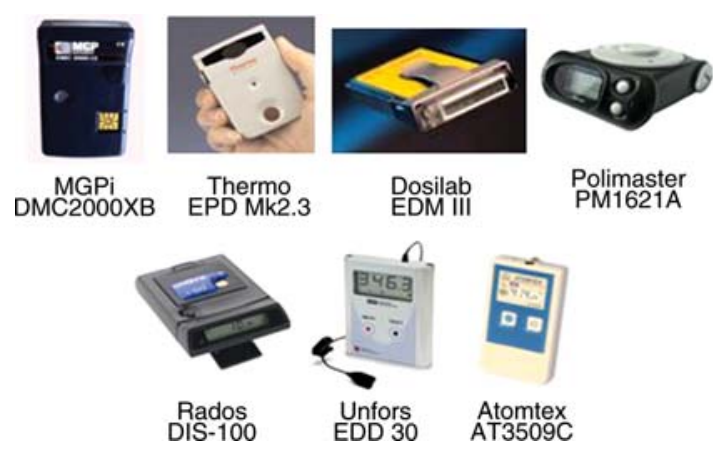

Figure 1. APDs tested in this study.
- the effect of the pulse frequency from 1 to $20 \mathrm{~s}^{-1}$ for a dose equivalent rate $=1.8 \mathrm{~Sv} \mathrm{~h}^{-1}$ and a pulse duration $=20 \mathrm{~ms}$ (tests were performed in a multi-pulsed mode);

- the effect of the pulse width from 20 to $1000 \mathrm{~ms}$ for a dose equivalent rate $=1.8 \mathrm{~Sv} \mathrm{~h}^{-1}$ (tests were performed in single pulsed mode); for technical reasons, tests under $20 \mathrm{~ms}$ were not possible.

\section{Tests of APDs under realistic conditions in hospitals}

A series of tests were made in 10 European hospitals during routine practice. The interventional radiologists and cardiologists were asked to wear, side by side and above their lead apron, an APD and an additional passive dosemeter during daily practice. The dosemeters were worn during several interventions to integrate doses of at least $300 \mu \mathrm{Sv}$ for several types of IR/IC procedures. The main objective of these tests was to compare the measurements performed by the active and passive dosemeters worn in routine practice in hospitals, where all kinds of procedures and parameter settings are used and without an accurate knowledge of the field parameters.

For practical reasons, only four dosemeters were tested in these realistic conditions: DMC 2000XB, EPD Mk2.3, EDM III and DIS-100.

\section{RESULTS}

\section{Typical fields in IR/IC}

The compilation of data presented in Table 1 gives an overview of typical fields encountered in IR/IC independently of the procedure considered.

The instantaneous dose equivalent rate obtained by quality control measurements using DAPmeters in the direct field at the level of the table ranges from 2 to $360 \mathrm{~Sv} \mathrm{~h}^{-1}$. The dose equivalent rate in the scattered beam, at the level of the operator for a tube position of $0^{\circ}$ and $90^{\circ}$, was found to range from $5 \cdot 10^{-3}$ to $\sim 10 \mathrm{~Sv} \mathrm{~h}^{-1}$. In

Table 1. Typical field characteristics encountered in IR/IC.

\begin{tabular}{ll}
\hline Parameter & \multicolumn{1}{c}{ Range } \\
\hline High peak voltage & $50-120 \mathrm{kV}$ \\
Intensity & $5-1000 \mathrm{~mA}$ \\
Inherent Al equivalent filtration & $4.5 \mathrm{~mm}$ \\
Additional Cu filtration & $0.1-0.9 \mathrm{~mm}$ \\
Pulse duration & $1-20 \mathrm{~ms}$ \\
Pulse frequency & $1-30 \mathrm{~s}^{-1}$ \\
$\begin{array}{l}\text { Dose equivalent rate in the direct } \\
\text { beam (table) }\end{array}$ & $2-360 \mathrm{~Sv} \mathrm{~h}^{-1}$ \\
$\begin{array}{l}\text { Dose equivalent rate in the } \\
\text { scattered beam (operator-above } \\
\text { the lead apron) }\end{array}$ & $5 \times 10^{-3}$ to $10 ~ \mathrm{~Sv} \mathrm{~h}^{-1}$ \\
\hline
\end{tabular}


addition, Monte Carlo calculations showed that the influence of the filtration on the scattered spectra is very small. The energy of the scattered spectra ranges from 20 to $100 \mathrm{keV}$.

\section{Response of APDs in a continuous mode}

In a continuous mode, all APDs have a linear response with the dose. The energy response

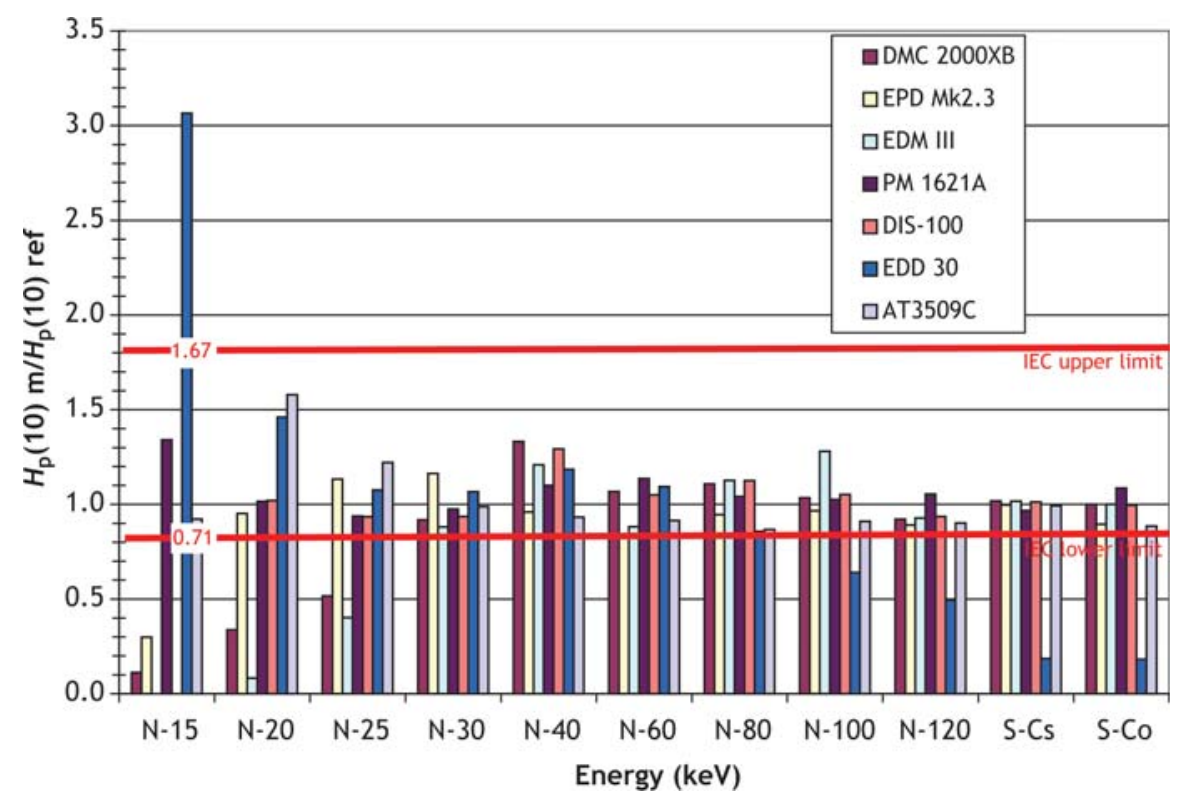

Figure 2. Energy response of APDs in a continuous mode (for a dose equivalent rate $H_{\mathrm{p}}(10)$ around $10 \mathrm{mSv} \mathrm{h}^{-1}$, and an integrated dose equivalent around $0.5 \mathrm{mSv}$ ).

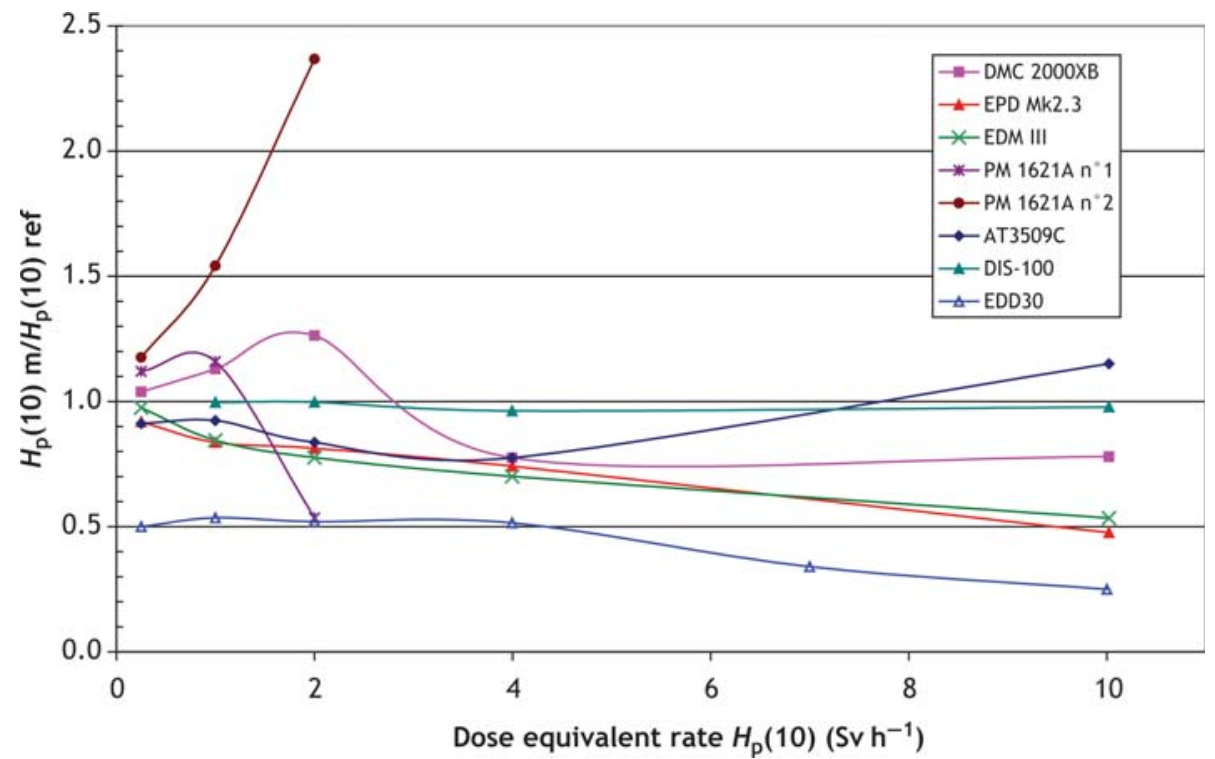

Figure 3. The dose equivalent rate response of APDs in a continuous mode (except for PM1621A, whose response diverged, the mean value of the two units of each APD type is represented). 


\section{CLAIRAND ET AL.}

(Figure 2) is within the interval $(0.71-1.67)$ as required in the IEC 61526 standard ${ }^{(10)}$ from ${ }^{60} \mathrm{Co}$ energy down to N-30 for all APDs except EDD30. For EDD30, these results are consistent with the fact that this APD is designed to work specifically at low energy.
Figure 3 illustrates the response of the selected APDs as a function of the dose equivalent rate. Most tested APDs provide a response for dose equivalent rates up to $10 \mathrm{~Sv} \mathrm{~h}^{-1}$, except PM1621A, for which the response diverges rapidly from 1 $\mathrm{Sv} \mathrm{h}^{-1}$, and EDD30, which saturates for dose

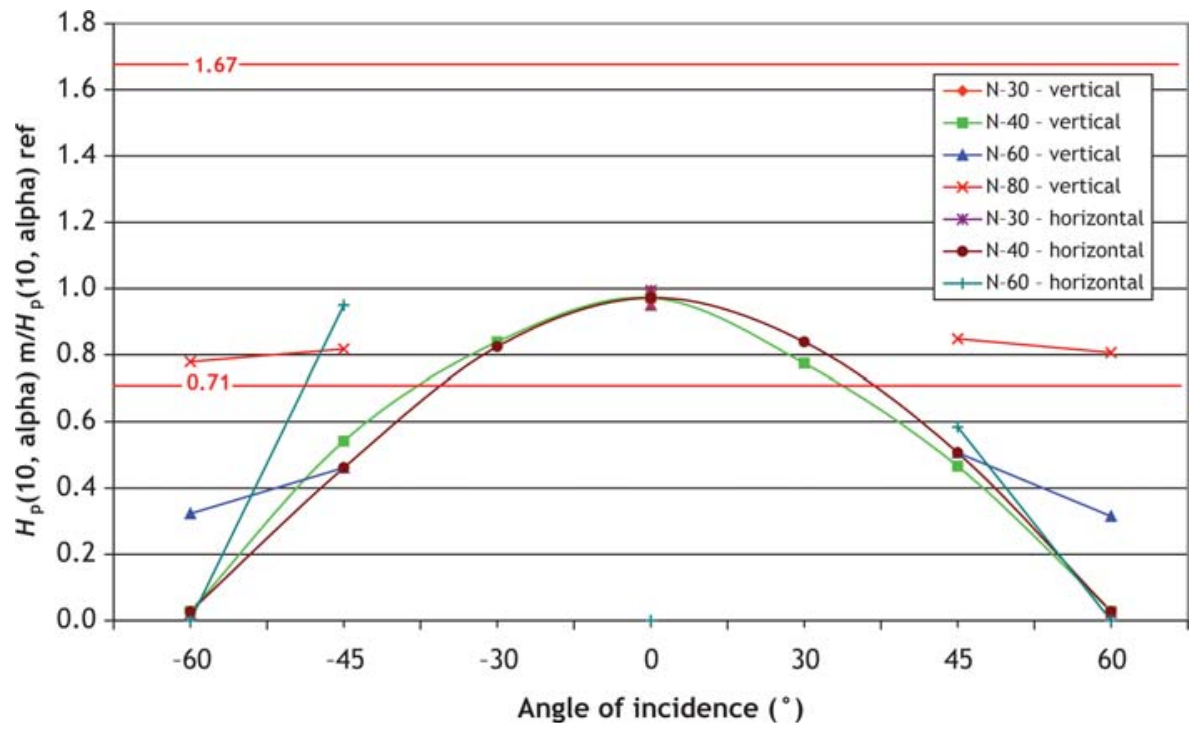

Figure 4. Response of AT3509C at different photon radiation energies and angles of incidence in a continuous mode.

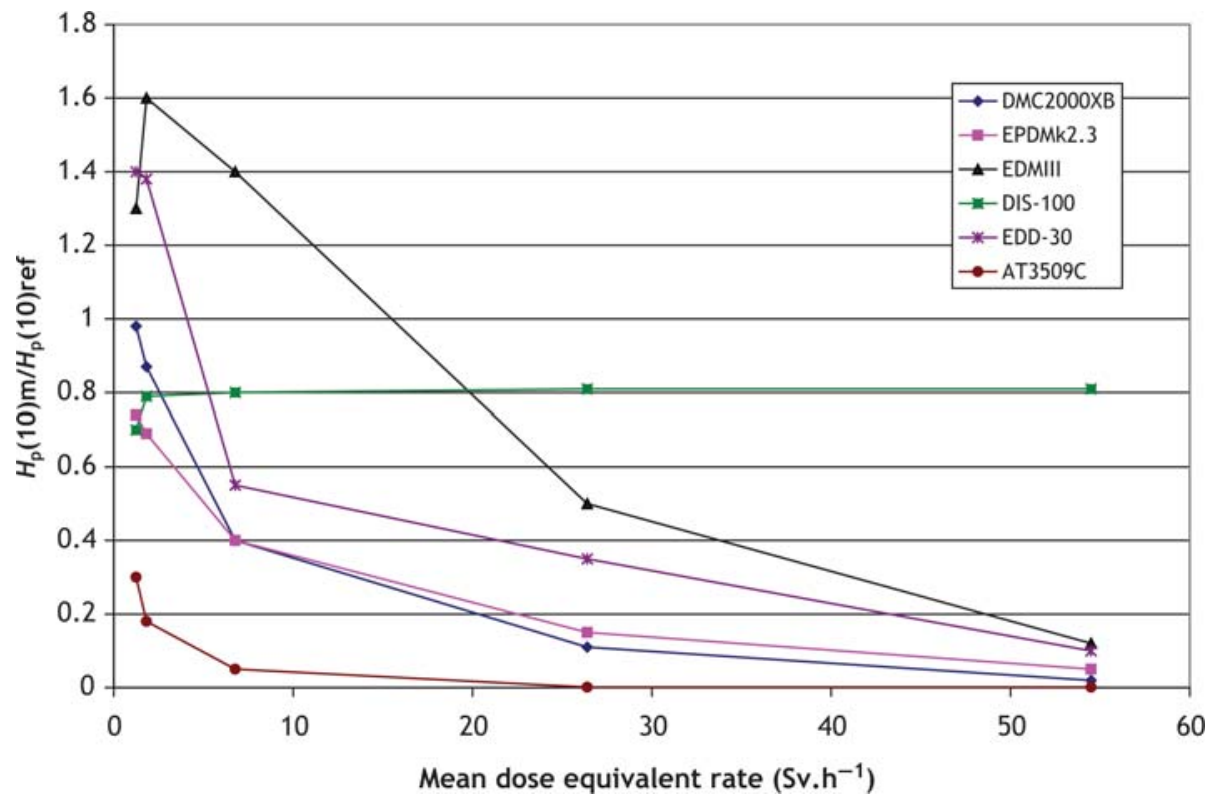

Figure 5. The dose equivalent rate response of APDs in a pulsed mode for a pulse frequency equal to $10 \mathrm{~s}^{-1}$. 
equivalent rates above $2 \mathrm{~Sv} \mathrm{~h}^{-1}$. The dose equivalent rate range requirement specified in IEC $61526^{(10)}$ is $1 \mathrm{~Sv} \mathrm{~h}^{-1}$; thus all the dosemeters fulfil the IEC standard.

All devices showed under and over-responses for low-energy photons and high angles, but these stayed within the limits of the IEC standard ${ }^{(10)}$ except AT3509C (Figure 4) for which the angle response is inside this interval at $60^{\circ}$ only from N-80.

\section{Response of APDs in a pulsed mode}

\section{Effect of the dose equivalent rate}

For most APDs, the response decreases when the dose equivalent rate increases (Figure 5). For dose equivalent rates lower than $2 \mathrm{~Sv} \mathrm{~h}^{-1}$, the responses are, in general, close to 1 and fall down more or less rapidly for higher dose rates, except DIS-100 which gives a correct response up to $55 \mathrm{~Sv} \mathrm{~h}^{-1}$.

\section{Effect of the pulse frequency}

Table 2 sums up the effect of the pulse frequency as a percentage of variation in the APD response between 1 and $20 \mathrm{~s}^{-1}$. This variation is roughly equal to $30 \%$ for all devices, except PM1621A (no signal) and EDD30 for which a saturation was observed from $2 \mathrm{~Sv} \mathrm{~h}^{-1}$.

\section{Effect of the pulse width}

When the pulse width is larger than $1 \mathrm{~s}$, the responses in the pulsed and continuous radiation fields are quite similar. No significant effect of the pulse width was observed.

Table 2. Effect of the pulse frequency $\left(1-20 \mathrm{~s}^{-1}\right)$ : percentage of variation on the APD response for a dose equivalent rate $=1.8 \mathrm{~Sv} \mathrm{~h}^{-1}$ and a pulse duration $=20 \mathrm{~ms}$.

\begin{tabular}{|c|c|c|c|c|c|c|c|}
\hline APD & $\begin{array}{c}\text { DMC } \\
2000 X B\end{array}$ & $\begin{array}{c}\text { EPD } \\
\text { MK2.3 }\end{array}$ & $\begin{array}{c}\text { EDM } \\
\text { III }\end{array}$ & PM1621A & $\begin{array}{c}\text { DIS- } \\
100\end{array}$ & EDD30 & AT3509C \\
\hline $\begin{array}{l}\text { Variation on the } \\
\text { APD response }(\%)\end{array}$ & $25-30$ & $30-40$ & $<10$ & No signal & 30 & $\begin{array}{l}10\left(1.8 \mathrm{~Sv} \mathrm{~h}^{-1}\right) \\
\text { saturation from } 2 \mathrm{~Sv} \\
\mathrm{~h}^{-1}\end{array}$ & $\begin{array}{l}30\left(10-20 \mathrm{~s}^{-1}\right) \mathrm{no} \\
\text { signal at } 1 \mathrm{~s}^{-1}\end{array}$ \\
\hline
\end{tabular}

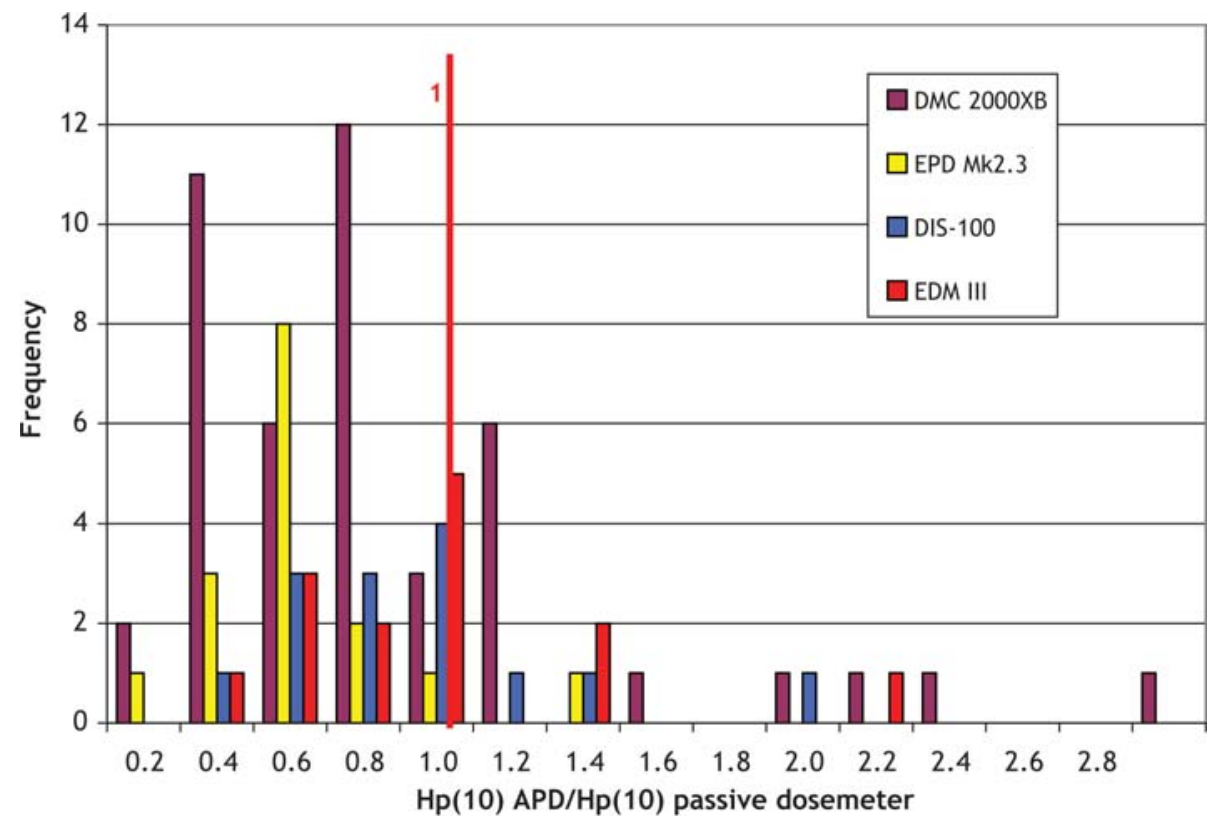

Figure 6. Distribution of the APD response compared with the passive dosemeter response in realistic conditions. 


\section{CLAIRAND ET AL.}

All results from the pulsed field tests show that the more continuous the field tends to be, that is, to say the longer the pulses and the higher the frequency, the more satisfactory the behaviour of the devices.

These results show that it is important to add tests in a pulsed mode when type-testing APDs, and thus the IEC $61526^{(10)}$ standard should be revised.

\section{Response of APDs in hospitals}

The results of tests performed in hospitals are presented in Figure 6 as the distribution of APD readings normalised to the passive dosemeter reading.

With respect to passive dosemeters, DMC 2000XB (median 0.65), EPD Mk2.3 (median 0.69), DIS-100 (median 0.78) and EDM III (median 0.81), on an average, present an under-response. The behaviour of APDs is globally more satisfactory in hospitals than in laboratories because devices are mainly exposed to scattered fields.

\section{CONCLUSION}

The tests performed with continuous X-ray beams showed that all APDs have a satisfactory response at lower energies typical of IR/IC. Most APDs provide a correct response for dose equivalent rates up to 10 $\mathrm{Sv} \mathrm{h}^{-1}$, except PM1621A, for which the response diverges rapidly from $1 \mathrm{~Sv} \mathrm{~h}^{-1}$, and EDD30, which saturates above $2 \mathrm{~Sv} \mathrm{~h}^{-1}$. However, the dose equivalent rates in the direct beam can be much higher than those tested here. So these tests cannot guarantee that the APDs will correctly measure the high dose equivalent rates in the direct beam.

The study in a pulsed mode showed that, except PM1621A, whose display does not give any indication, all APDs provide a reading. The tests performed in laboratory conditions with pulsed X-ray fields determined the effect of the dose rate, pulse frequency and pulse width on the APD response. First, for most APDs, the response is generally equal to 1 for dose equivalent rates lower than $2 \mathrm{~Sv} \mathrm{~h}^{-1}$, and decreases for higher dose rates, except DIS-100 which gives a correct reading for high dose rates. Second, for a pulse frequency ranging from 1 to $20 \mathrm{~s}^{-1}$, a variation of $30 \%$, on an average, is observed for all APDs. Finally, no significant effect of the pulse width was observed.

The measurements in hospitals confirmed an under-response of APDs (median ranging from 0.65 to 0.81 ) with respect to passive dosemeters.

Since all selected APDs, except PM1621A, provide a reading in the pulsed mode, this means they could be used in routine monitoring at hospitals, provided correction factors are introduced ${ }^{(11)}$. Some preliminary guidelines with recommendations on how to use APDs in practice were presented at IRPA2010 $0^{(12)}$.

\section{FUNDING}

This study has received funding from the European Atomic Energy Community's 7th Framework Program (FP7/2007-2011 - grant agreement no. 211361).

\section{REFERENCES}

1. ORAMED. Available on http://www.oramed-fp7.eu/.

2. Ginjaume, M., Bolognese-Milsztajn, T., LuszikBhadra, M., Vanhavere, F., Wahl, W. and Weeks, A. Overview of active personal dosemeters for individual monitoring in the European Union. Radiat. Prot. Dosim. 125(1-4), 261-266 (2007).

3. Clairand, I. et al. Intercomparison of active personal dosemeters in interventional radiology. Radiat. Prot. Dosim. 129(1-3), 340-345 (2008).

4. Bordy, J.-M., Daures, J., Clairand, I., Denozière, M., Donadille, L., d'Errico, F., Gouriou, J., Itié, C. and Struelens, L. Evaluation of active personal dosemeters for interventional radiology. Radiat. Prot. Dosim. 131(1), 87-92 (2008).

5. International Atomic Energy Agency. Intercomparison of personal dose equivalent measurements by active personal dosimeters. Final Report of a joint IAEA EURADOS Project. IAEA Report IAEA-TECDOC1564. IAEA (2007).

6. Pelowitz, D. B. (Ed.). MCNPX user's manual, $M C N P X$ version 2.5.0. Report LA-CP-05-0369. Los Alamos National Laboratory (2005).

7. Salvat, F. PENELOPE 2006: A code system for Monte Carlo simulation of electron and photon transport. In: Workshop Proceedings Barcelona, Spain, 4-7 July 2006, OECD 2006 NEA No. 6222, Nuclear Energy Agency Organisation for Economic Co-operation and Development (2006).

8. International Organization for Standardization. $X$ and gamma reference radiation for calibrating dosemeters and doserate meters and for determining their response as a function of photon energy-part 1: radiation characteristics and production methods. ISO 4037. ISO (1996).

9. Denozière, M., Bordy, J.-M., Daures, J. and Lecerf, N. $P$ ulsed $X$-rays for interventional radiology: test on active personal dosemeters (APD) European project FP7 ORAMED WP3. Report CEA-R-6233 (CEA) (2009).

10. International Electro Technical Commission (IEC). Radiation protection instrumentation. Measurement of personal dose equivalent $H p(10)$ and $H p(0.07)$ for $X$, gamma, neutron and beta radiation: direct reading personal dose equivalent and/or dose equivalent rate dosemeters. IEC 61526 (IEC) (2005).

11. Ambrosi, P., Borowski, M. and Iwatschenko, M. Considerations concerning the use of counting active personal dosemeters in pulsed fields of ionising radiation. Radiat. Prot. Dosim. 139, 483-493 (2010).

12. Clairand, I. et al. Guidelines for the use of APDs in interventional radiology. In: Proceedings of IRPA2010, Helsinki (2010). 